\title{
Do living ex situ collections capture the genetic variation of wild populations? A molecular analysis of two relict tree species, Zelkova abelica and Zelkova carpinifolia
}

\author{
Camille Christe • Gregor Kozlowski • David Frey • \\ Laurence Fazan - Sébastien Bétrisey • Stergios Pirintsos • \\ Joachim Gratzfeld • Yamama Naciri
}

Received: 11 February 2014/Revised: 12 June 2014/Accepted: 2 July 2014 /

Published online: 17 July 2014

(C) Springer Science+Business Media Dordrecht 2014

\begin{abstract}
Botanic gardens and arboreta, particularly in regions where iconic relict trees naturally occur, play a vital role in the conservation of these species. Maintaining wellmanaged living ex situ collections of rare and threatened relict tree species provides an immediate insurance policy for the future species conservation. The aim of this research was to investigate the origin, representativeness and genetic diversity of relict trees kept in botanic gardens and arboreta. We used as a model two ecologically and biogeographically distinct members of the prominent relict genus Zelkova (Ulmaceae), which survived the last glaciation in disjunct and isolated refugial regions: Z. carpinifolia in Transcaucasia and Z. abelicea endemic to Crete (Greece) in the Mediterranean. Our study revealed substantial differences in the genetic diversity and the origin of living ex situ collections of the two
\end{abstract}

Communicated by Neil Brummitt.

Electronic supplementary material The online version of this article (doi:10.1007/s10531-014-0756-9) contains supplementary material, which is available to authorized users.

C. Christe · G. Kozlowski · D. Frey · L. Fazan · S. Bétrisey

Department of Biology and Botanic Garden, University of Fribourg, Chemin du Musée 10, 1700 Fribourg, Switzerland

C. Christe - Y. Naciri

Unité de Phylogénie et Génétique moléculaires, Conservatoire et Jardin botaniques,

Chambésy, 1292 Chambésy, Geneva, Switzerland

G. Kozlowski · S. Bétrisey

Natural History Museum, Chemin du Musée 6, 1700 Fribourg, Switzerland

D. Frey · L. Fazan

Conservation Biogeography Group, Department of Geosciences, University of Fribourg,

Chemin du Musée 4, 1700 Fribourg, Switzerland

S. Pirintsos

Department of Biology, University of Crete, P.O. Box 2208, 71409 Heraklion, Crete, Greece 
investigated taxa. The living ex situ collections of $Z$. carpinifolia have relatively high representativeness compared with the global genetic variability of natural stands identified in a previous study. In contrast, Z. abelicea, which possesses an extraordinarily high genetic variability in natural populations, is clearly underrepresented in botanic garden collections. Moreover, all Z. abelicea trees investigated in this study most probably originated from a single region, the Levka Ori in western Crete. Thus, the ex situ conservation of $Z$. abelicea requires major planning and coordination efforts, including the establishment of well-documented collections in botanic gardens in Greece and especially on Crete. New living ex situ collections should be created using plant material collected from all of the mountain regions where $Z$. abelicea still occurs. Our study highlights the need for re-evaluating the existing living ex situ collections of trees and the development of new strategies for future conservation efforts in botanic gardens and arboreta. The coordination of conservation efforts between gardens must be enhanced to prioritize actions for the most threatened relict tree species.

Keywords Botanic gardens - Chloroplast markers - Conservation strategy · Living ex situ collections - Genetic diversity

\section{Introduction}

Recent molecular data and phylogeographic analyses demonstrate that tree species represent a remarkable evolutionary heritage for the conservation of plant diversity (Petit et al. 2005). Among them, relict tree species provide a unique opportunity to understand past and recent biogeographical and evolutionary processes. Their scientific value is therefore inestimable (Connor 2009).

Although relict tree species have attracted the attention of scientists for many centuries and their cultivation in botanic gardens and arboreta has a long tradition (Maunder et al. 2004), most collections were not established with conservation purposes in mind. In the past, much of the interest focused on the exploitation of trees with economic or ornamental potential. Only in the last half of the twentieth century did living ex situ collections gain substantial interest as conservation tools (Donaldson 2009). Today, the ex situ conservation of components of biological diversity is perceived as one of the most important methods for preserving species and is complementary to in situ conservation (Maunder et al. 2004; Primack 2004). However, the notorious lack of resources limits the ex situ conservation of rare and threatened plants in botanic gardens, especially long lived and large trees (Oldfield 2009; Wyse Jackson and Kennedy 2009; BGCI 2010).

S. Pirintsos

Botanic Garden, University of Crete, Gallos Campus, 74100 Rethymnon, Crete, Greece

J. Gratzfeld

Botanic Gardens Conservation International (BGCI), 199 Kew Road, Richmond, Surrey TW9 3BW, United Kingdom

Y. Naciri $(\bowtie)$

Laboratoire de Systématique végétale et Biodiversité, University of Geneva, 1292 Chambésy, Geneva, Switzerland

e-mail: yamama.naciri@ville-ge.ch 
The maintenance of living ex situ collections has saved many endangered relict tree species from extinction, with the most illustrative example being Ginkgo biloba (Chaw et al. 2000; Oldfield 2009). The same conservation strategy was undertaken after the discovery of the Wollemi Pine (Wollemia nobilis, Araucariaceae) in Australia. Living ex situ collections of this tree were quickly established, followed by the intensive commercial breeding and the distribution of young trees to botanic institutions and arboreta across the world (Trueman et al. 2007). Such "domestication for conservation", although somehow controversial, should efficiently secure the long-term survival of this 'living fossil', for which fewer than 100 highly threatened individuals still exist in the wild.

Three of the main problems with the living ex situ tree collections kept in botanic gardens and arboreta are the sizes and origins of these collections, together with their genetic representativeness (Kozlowski et al. 2012a). Although the need to address these challenges has been recognized for many years (e.g., Ledig 1988; Cohen et al. 1991; Yang and Yeh 1992; Etisham-Ul-Haq et al. 2001), no significant improvements have been made in the last several decades (Ensslin et al. 2011; Rucinska and Puchalski 2011; Kozlowski et al. 2012a). Namoff et al. (2010) proposed, for example, to collect at least 15 plants, preferably from 3 populations for the purpose of maintaining genetic diversity. Other researchers suggested, however, that to establish a genetically representative living ex situ collection, some 50 populations per species and a minimum of 50 individuals per population should be represented per collection (Brown and Marshall 1995).

In the Northern Hemisphere, many relict tree species survived the last glaciation only in isolated and disjunct refugial regions or on Mediterranean islands (Quézel and Médail 2003; Garfî et al. 2011; Kozlowski and Gratzfeld 2013). The genus Zelkova (Ulmaceae) is one of these emblematic relicts. Today, this genus comprises six extant species showing a disjunct distribution: three species occur in eastern Asia (Z. serrata, Z. schneideriana and Z. sinica), Z. carpinifolia grows in Transcaucasia, and Z. sicula and Z. abelicea occur in the Mediterranean region (Burnham 1986; Wiegrefe et al. 1998; Zheng-yi and Raven 2003; Denk and Grimm 2005). In a recent study using two chloroplast and two nuclear molecular markers on 154 individuals from 30 in situ populations, Christe et al. (2014) showed, that the three Eurasian species are highly structured according to geography and that both $Z$. carpinifolia and Z. abelicea exhibit an important molecular polymorphism. These results delivered the necessary basis for estimating the genetic representativeness of Zelkova living ex situ collections.

The present study sought, therefore, to determine how much of the genetic variation within a relict tree species is captured through living ex situ collections. We concentrated our investigations on the two Zelkova species from western Eurasia: Z. abelicea, endemic to Crete (Greece), and Z. carpinifolia, which grows naturally in the Transcaucasian countries of western Asia (Turkey, Georgia, Armenia, Azerbaijan and Iran; Phitos et al. 1995; Güner and Zielinski 1998; Søndergaard and Egli 2006; Kozlowski and Gratzfeld 2013). These two species differ in many aspects of their biology, ecology and conservation status. Zelkova abelicea is a mountainous tree growing between 900 and 1,800 m a.s.l. (Kozlowski et al. 2012a, 2014). Together with Acer sempervirens, Quercus coccifera and Cupressus sempervirens, it forms small forest remnants, occurring primarily on the northfacing slopes of the Cretan mountains (Søndergaard and Egli 2006; Fazan et al. 2012; Bosque et al. 2014). Due to overgrazing by goats and sheep, habitat fragmentation and destruction, fires and water stress, this species is endangered (IUCN category EN, Kozlowski et al. 2012b). Zelkova carpinifolia has a much larger distribution area and is one of the most characteristic relict tree species of the Transcaucasian sub-tropical region (Kvavadze and Connor 2005; Kozlowski and Gratzfeld 2013). This area is considered one 
of the most important refugial zones for relict flora worldwide (Milne and Abbott 2002; Milne 2006). Although locally rare and threatened, Z. carpinifolia still forms relatively large lowland forests in several parts of its range. It grows there together with other relicts such as Albizia julibrissin, Diospyros lotus, Parrotia persica, Pterocarya fraxinifolia and Gleditsia caspica (Browicz and Zielinski 1982; Mai 1995; Kozlowski and Gratzfeld 2013). The IUCN red list has assigned this species to the category near threatened (NT, Güner and Zielinski 1998). The third taxon of western Eurasia, Z. sicula from Sicily, was not included in our study because of its exceptional situation. This narrow endemic tree was discovered in 1991, and only one population was known worldwide until recently. There are only five known living ex situ collections in Sicily and abroad, which all originated from this unique population (Di Pasquale et al. 1992; Garfî 2006). Additionally, all plants are triploid and show a very low genetic diversity (Christe et al. 2014). They are suspected to reproduce exclusively clonally (Garfî et al. 2011; Kozlowski and Gratzfeld 2013).

Since Christe et al. (2014) showed that most haplotypes can be assigned geographically to small regions, we addressed the following specific questions: (1) How do the origins of the $Z$. abelicea and $Z$. carpinifolia trees in living ex situ collections compare with the locations of wild populations? (2) What is the level of genetic representativeness of the living ex situ collections compared with the global genetic variability of $Z$. abelicea and $Z$. carpinifolia stands? (3) What is the level of genetic variation in living ex situ collections in comparison with that in natural populations of both species? (4) Is the most threatened species, Z. abelicea, well represented and thus safeguarded through living ex situ conservation? (5) What is the level of misidentification and errors in living ex situ collections? The genetic survey presented in this paper sheds light on the shortfalls in the conservation of relict trees through living ex situ collections. The conclusions are also of wider relevance for other threatened plant species.

\section{Methods}

\section{Sampling}

Botanic gardens and arboreta with available living ex situ collections were contacted after a global survey addressing the representativeness of the genus Zelkova in living ex situ collection (Kozlowski et al. 2012a). Leaf material was received or collected by ourselves in botanic gardens and arboreta worldwide interested to participate to the study. The focus was placed on collections that have more than two individuals of at least one of these species in order to estimate diversity within the institutions. Exceptions were however considered for Jardins des Plantes et Arboretum de Chevreloup, France, and Conservatoire et Jardin botanique de la Ville de Genève (CJBG), Switzerland, with only one individual (see online Appendix). Parc Floraire, Switerland, was not included in the first survey but was added later on, because of the number and age of the individuals.

After this selection, a total of 31 botanic gardens and arboreta were retained, representing 119 individuals, among which 100 were labeled as Z. abelicea (31) and Z. carpinifolia (69).

The remaining 19 individuals were samples of the three Asian species, Z. serrata (8), $Z$. sinica (3) and Z. schneideriana (8) that were used as references, whatever the number of individuals in botanical collections, as long as the sampling location was known (see online Appendix). All the samples concerning the three Asian species have already been published in the study of Christe et al. (2014). 
DNA extraction, amplification and sequencing

Total genomic DNA was extracted using the NucleoSpin (C Plant II kit (Macherey-Nagel) following the supplier's instructions. One cpDNA spacer (trnH-psbA; Shaw et al. 2005) and one cpDNA intron (trnL; Taberlet et al. 1991) were amplified and sequenced. PCR amplifications and sequencing were performed as indicated in Christe et al. (2014).

Data analyses

All sequences were assembled using the program Sequencher (GeneCodes Corporation, Ann Arbor, Michigan, USA) and were manually aligned using BIOEDIT 7.0.3.5 (Hall 1999). Chloroplast DNA haplotypes were carefully checked and determined based on the aligned sequences. This analysis also included the haplotypes found for the in situ populations of Z. abelicea and Z. carpinifolia and those for ex situ individuals from the three Asian species of the same genus (Z. schneideriana, Z. serrata and Z. sinica; Christe et al. 2014).

Prior to analysis, indels and inversions, commonly found in trnH-psbA (Whitlock et al. 2010), were manually coded to be counted as single mutation steps using Barriel's rules (Barriel 1994). Indel and inversion events were then taken into account in all analyses, as these events have been shown to provide relevant phylogeographical information (Christe et al. 2014). Haplotype sequences were submitted to GenBank under accessions numbers JX399108-JX399112, JX399121-JX399122, JX399136, JX399139-JX399147. The gene and nucleotide diversities ( $h$ and $\pi$, respectively) as well as their standard deviations (SD) were calculated per population and per species using ARLEQUIN version 3.1.5.2 (Excoffier et al. 2005). Gene diversities, that are corrected for sampling size (Nei 1973), were compared at the species level only, and declared significantly different at the $5 \%$ level when their confidence intervals $(h \pm 2 \mathrm{SD})$ did not overlap. In order to compare the number of haplotypes recorded in situ and ex situ for a given species, a rarefaction method was used to take into account differences in sample sizes. The rarefaction size was set to 31 and 62 for $Z$. abelicea and $Z$ carpinifolia, respectively, as the sampling sizes in situ were higher than ex situ [67 and 77, respectively; Christe et al. (2014)]. The analysis was performed using the software CONTRIB following Petit et al. (1998). Finally, a median-joining network of the combined chloroplast haplotypes was constructed using the software Network (Bandelt et al. 1999).

\section{Results}

The two cpDNA loci were aligned and combined. Based on 1,604 bp consensus alignment, 14 haplotypes were detected for Z. abelicea and Z. carpinifolia (Table 1). Among these haplotypes, eight were already found by Christe et al. (2014), and six were newly sequenced (Figs. 1, 2).

\section{Zelkova abelicea}

A total of 31 individuals from eight botanic gardens were sequenced (see online Appendix). Only two different haplotypes (XJ and X2J) were found, (Fig. 1b). Haplotype XJ was already known (Christe et al. 2014), but X2J was a newly sequenced haplotype, separated by four mutations from XJ, VJ and KJ (Fig. 1a). In situ analyses indicate that haplotype XJ 


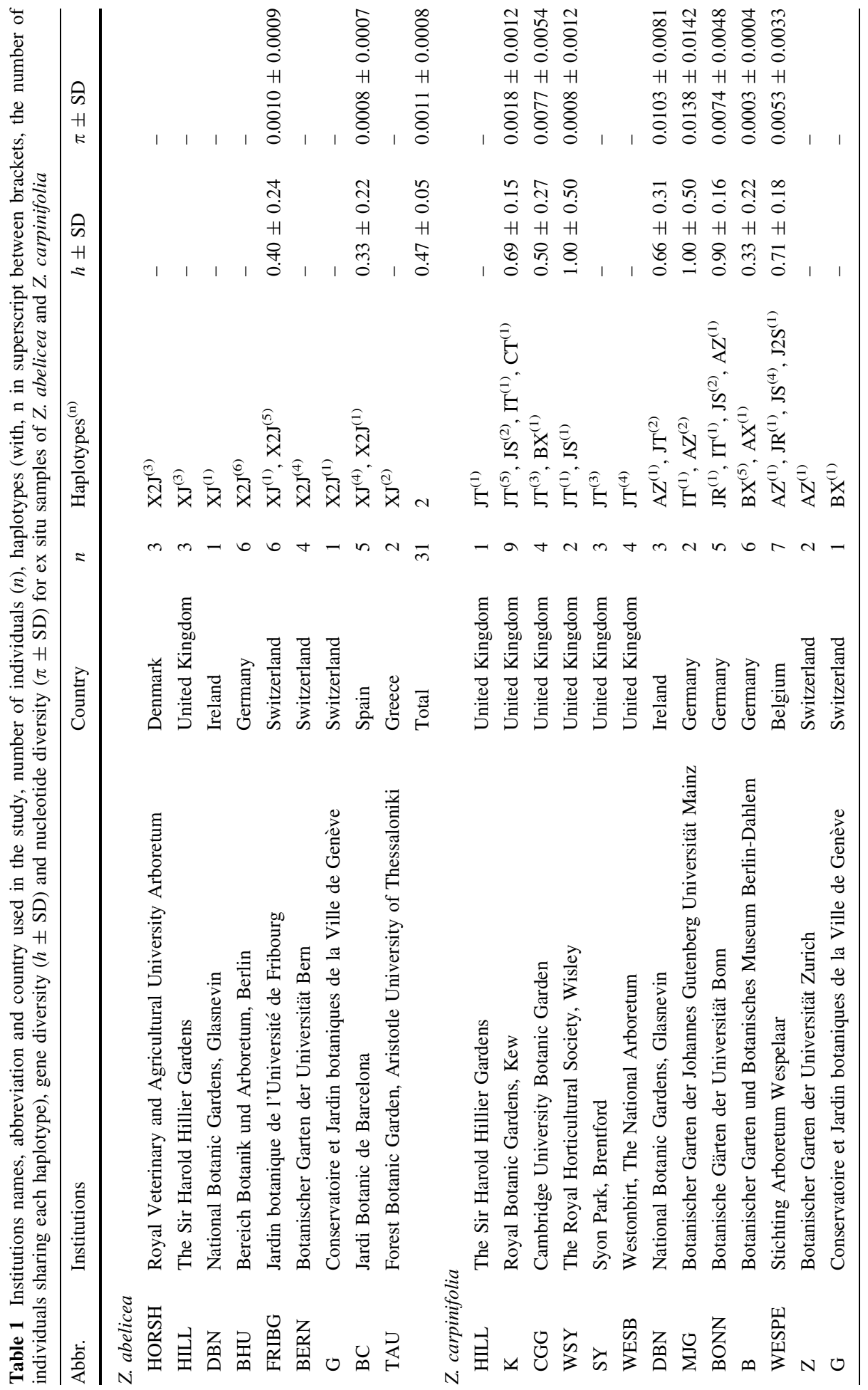




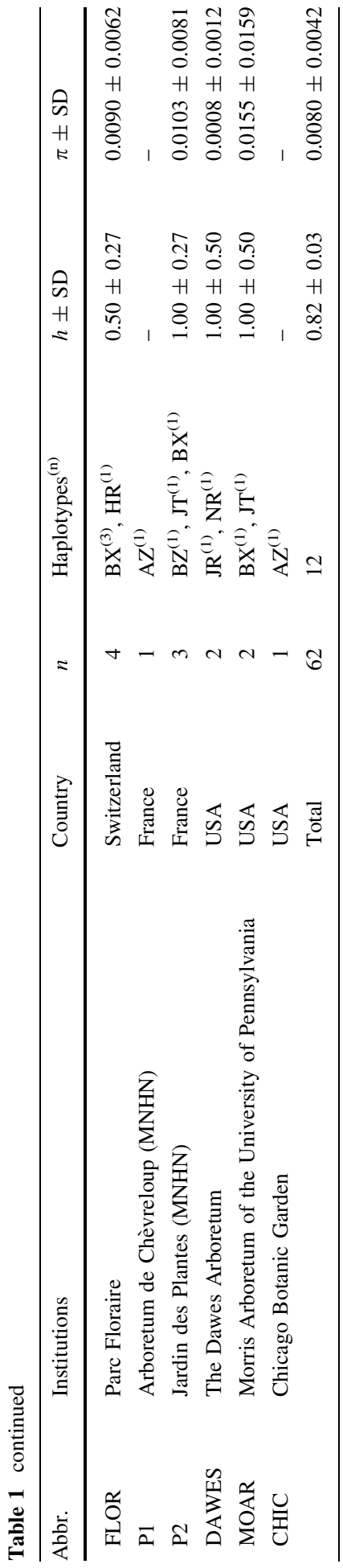


a
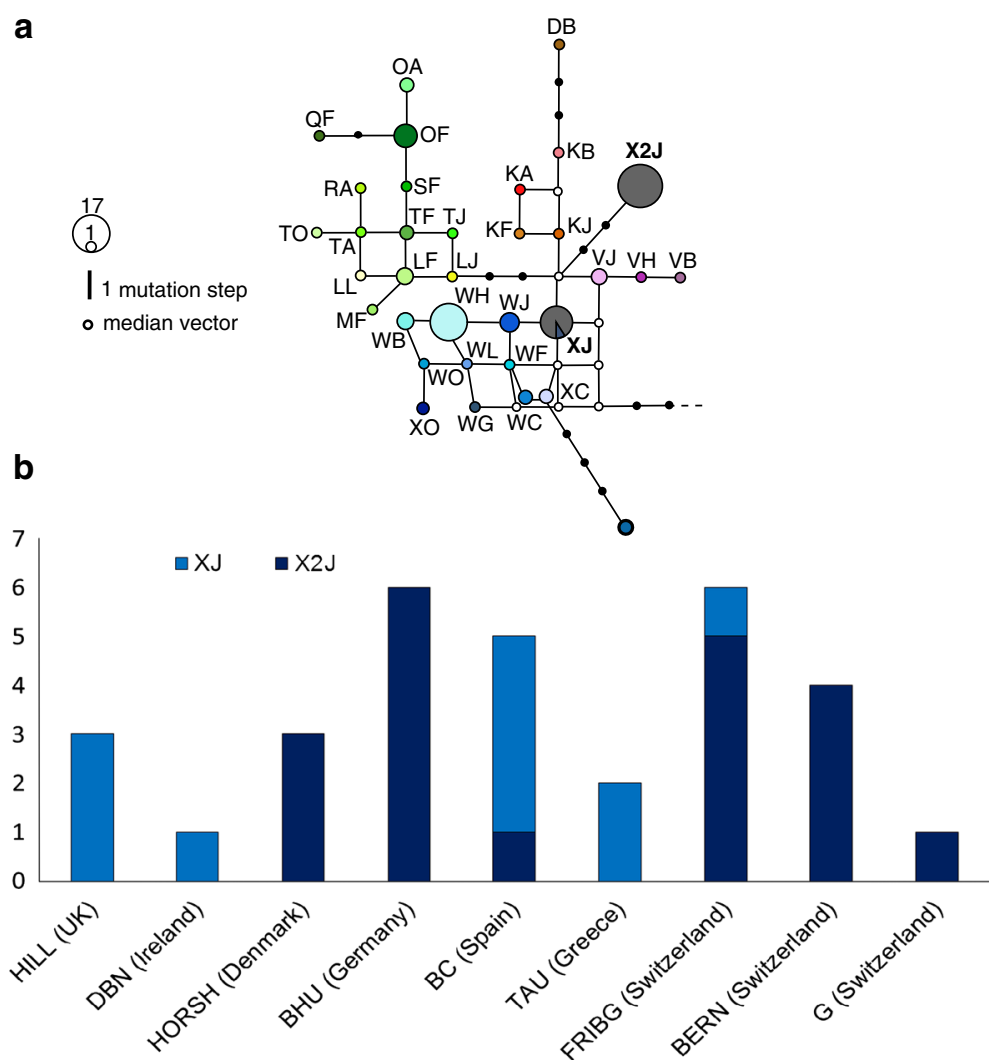

Fig. 1 a Median-joining network for the combined Z. abelicea haplotypes. The size of each haplotype is proportional to the number of individuals that share it. It considers the 31 ex situ individuals of this study and 67 in situ individuals published in Christe et al. (2014). Ex situ individuals are represented in grey and individuals sampled in natural populations in colours. b Haplotypes of Z. abelicea detected in the surveyed ex situ collections (31 individuals from 9 botanic gardens). Haplotype names and abbreviations of the botanic gardens are given in Table 1

and VJ are present in the western part of the island in the Lefka Ori mountains, (Omalos Plateau and Eligas gorge, respectively), whereas KJ is only found in the Thrypti mountains, east of the island. Haplotypes found by Christe et al. (2014) in Kedros, Psiloritis or Dikti (Central Crete) were not recovered in botanic collections. Only two botanic garden collections possess more than one haplotype: Fribourg and Barcelona (Fig. 1b) with gene diversities $(0.40 \pm 0.24$ and $0.33 \pm 0.22$, respectively) and nucleotide diversities $(0.0010 \pm 0.0009$ and $0.0008 \pm 0.0007$, respectively) falling within similar ranges. The rarefaction analysis indicates that subsampling at random 31 individuals within the 67 in situ individuals would have led to a mean number of haplotypes of 19.1 instead of the 33 actually seen. This is much greater than the two haplotypes recorded for the $31 \mathrm{ex}$ situ individuals. Gene diversity was also found significantly lower ex situ than in situ ( $h=0.47 \pm 0.05$ and $h=0.92 \pm 0.02$, respectively). 
a

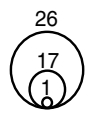

1 mutation step - median vector
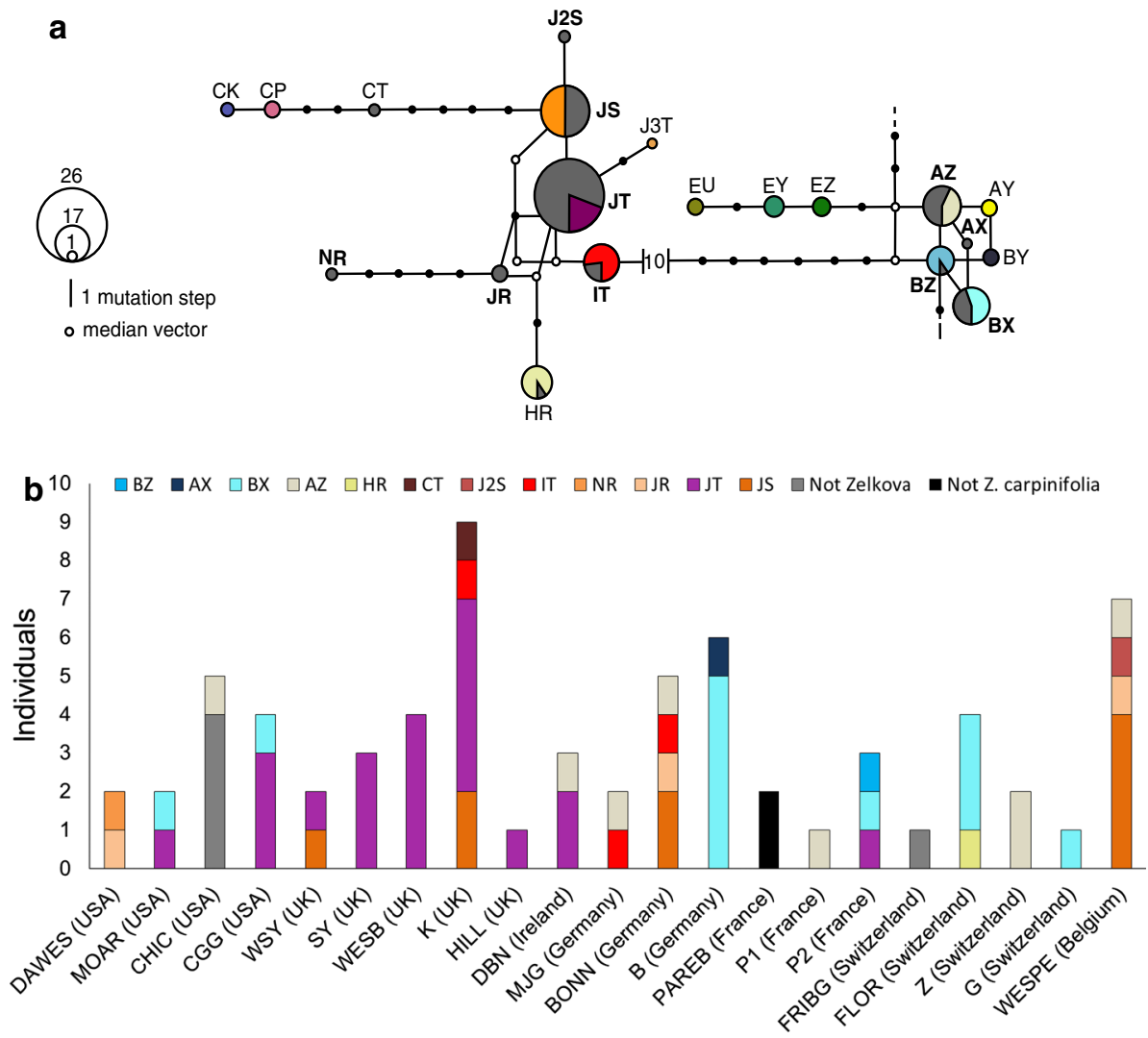

Fig. 2 a Median-joining network for the combined Z. carpinifolia haplotypes. The size of each haplotype is proportional to the number of individuals that share it. It considers the 62 ex situ individuals presented in this study and 77 in situ individuals published in Christe et al. (2014). Ex situ individuals are represented in grey and individuals sampled in natural populations in colours. b Haplotypes of Z. carpinifolia detected in ex situ collections (69 individuals from 21 botanic gardens). Haplotype names and abbreviations of the botanic gardens are given in Table 1

\section{Zelkova carpinifolia}

A total of 69 individuals from 21 botanic gardens were sequenced (Table 1; see online Appendix; Fig. 2). Two individuals were identified as not being Z. carpinifolia because they displayed haplotypes of the Asian Zelkova species (both from Jardin botanique de la ville de Paris, Ecole de Breuil, PAREB, France). Moreover, five individuals were identified as not belonging to the Zelkova genus (Fig. 2b): four from the Chicago Botanic Garden USA (CHIC) and one from the Fribourg Botanical Garden Switzerland (FRIBG). Blast analysis of the sequences in Genbank showed that the four trees from Chicago could be Carpinus betulus or Ostrya (Betulaceae) and the one coming from Fribourg could be an Ulmus species.

The remaining 62 individuals from 19 botanic garden collections displayed seven haplotypes that were already known (BX, BZ, AZ, IT, JT, JS, HR; Christe et al. 2014; Fig. 2a), three new haplotypes combinations (AX, JR and CT) and two new trnH-psbA 
sequences ( $\mathrm{J} 2$ and $\mathrm{N})$. These two sequences gave rise to two additional haplotypes, NR and $\mathrm{J} 2 \mathrm{~S}$, that are positioned close to known haplotypes in the network. Eight haplotypes (JS, J2S, JR, JT, CT, IT, HR and NR) and 40 individuals were found in the part of the network that contained clusters of individuals located in the eastern part of the distribution range of Z. carpinifolia whereas four haplotypes (AX, AZ, BX, BZ) and 22 individuals could be assigned to the western distribution range of $Z$. carpinifolia (Fig. 2a), according to Christe et al. (2014). Eleven botanic gardens $(63 \%)$ have collections displaying at least two different haplotypes, and seven of them (42\%) host individuals holding haplotypes that come from the two major diversity areas of $Z$. carpinifolia.

The gene diversities ranged between $0.33 \pm 0.22$ (Botanical Garden Berlin Dahlem) and $1.00 \pm 0.50$ (Mainz Botanical Garden, Germany; Royal Horticultural Society Wisley, UK; Morris Arboretum, USA; Dawes Arboretum, USA). The nucleotide diversities differed more greatly, ranging from $0.0003 \pm 0.0004$ (Mainz Botanical Garden, Germany) to $0.0155 \pm 0.0159$ (Morris Arboretum, USA). Rarefaction analysis indicates that subsampling at random 62 individuals within the 77 in situ individuals would have led to a mean number of haplotypes of 14.7 instead of the 15 actually seen. This is higher than the 12 haplotypes found for the $62 \mathrm{ex}$ situ individuals (Table 1). Accordingly, gene diversity was found to be significantly higher in situ than ex situ $(h=0.93 \pm 0.01$ and $0.82 \pm 0.03$, respectively; Table 1).

\section{Discussion}

For many threatened plant species, maintaining living ex situ collections offers a fundamental insurance policy for the future (Oldfield 2009). The Global Strategy for Plant Conservation (GSPC), adopted at the Sixth Conference of the Parties to the Convention of Biological Diversity in 2002 and revised in 2011, calls for $75 \%$ of threatened plant species to be conserved in accessible ex situ collections (CBD 2011). However, although the ex situ cultivation of trees has very long tradition (Kozlowski et al. 2012a), the information available on the genetic diversity and representativeness of botanic garden collections is still very poor (Etisham-Ul-Haq et al. 2001; Namoff et al. 2010; Lauterbach et al. 2012). Moreover, genetic comparisons between wild populations and ex situ collections of relic trees are scarce (Del Tredici et al. 1992; Li et al. 2005; Namoff et al. 2010). As a consequence, thorough genetic investigations of living ex situ collections of many emblematic taxa, such as the genus Zelkova, are lacking.

Our study revealed substantial differences in the genetic diversity and origin of the ex situ collections of the two investigated Zelkova species. The Transcaucasian species, $Z$. carpinifolia, which is generally well represented in botanic garden collections (Kozlowski et al. 2012a), has a relatively high genetic representativeness compared with the global within-species genetic variability found in the natural stands analysed in our previous study (Christe et al. 2014). The twelve haplotypes detected in ex situ collections are derived from two genetically distant phylogeographic regions, with the majority of sampled trees $(65 \%)$ having their origin in the eastern cluster (Iran, Azerbaijan and eastern Georgia) and only $35 \%$ originating from the western cluster (Turkey and Georgian Colchis). For this species, 15 haplotypes were detected in the wild (Christe et al. 2014), seven of which were recovered in ex situ collections. Moreover, ex situ collections allowed the identification of five new haplotypes, leading to a total number of 20 haplotypes for the species. Although the sampling of Christe et al. (2014) aimed to be exhaustive, the significant increase in 
haplotype number $(+33 \%)$ due to ex situ collections clearly highlights their interest in preserving intraspecific diversity.

In contrast, the Cretan species Z. abelicea is clearly underrepresented in botanic garden collections. Although this species possesses an extraordinarily high genetic variability within and between natural populations, with 33 haplotypes detected by Christe et al. (2014), only two were found in investigated ex situ collections. In this case, the ex situ survey only increased the number of haplotypes by $3 \%$ for the species. Moreover, one of these haplotypes originated from a single region in the Omalos Plateau in the Lefka Ori (White Mountains), which is the most visited and collected area on Crete (Søndergaard and Egli 2006). The second haplotype, not recorded by Christe et al. (2014), can be assumed to have originated from the Lefka Ori or from Thrypti given its position in the network at equal distances from three haplotypes found in these two regions (VJ and XJ from Lefka Ori and KJ from Thrypti). However, it is almost impossible that any ex situ culture is coming from Thrypti. First, the population was discovered probably only in the 1980s and was known by few specialists before the present investigations were started. Second, the population is not producing seeds (only sterile browsed individuals). It is therefore very improbable that plant material from this population has served in the past as a source of any ex situ collection. The two former arguments therefore strongly suggest that the new haplotype also originates for Lefka Ori. The remaining mountain chains (Kedros, Psiloritis, Dhikti and probably Thrypti) with genetically distant $Z$. abelicea populations were most likely never collected for the establishment of old ex situ collections.

Our study clearly demonstrates that the most threatened species, Z. abelicea, is not safeguarded in the living ex situ collections investigated in this study. The ex situ conservation of this species therefore requires major planning and coordination efforts, including the establishment of well-documented collections in botanic gardens in Greece and especially on Crete. Ex situ cultures should be created using plant material collected from all of the mountain regions where Z. abelicea still occurs. In particular, the populations from small, threatened and highly isolated regions of the Cretan Mountains (Kedros, Psiloritisand Dhikti and Thrypti) need more attention. The Lefka Ori should also be better sampled since populations from this region are only represented by two haplotypes, whereas Christe et al. (2014) showed that it is the place where the highest diversity can be found with 16 haplotypes. The practical conservation and propagation efforts carried out by Egli (1995, 1997) and Søndergaard and Egli (2006) for Z. abelicea provide relevant guidance. Plants collected in the wild were cultivated in several botanic gardens, arboreta and private gardens on Crete, Switzerland, Norway and Denmark. A survey of these collections, which were not included in our study, may change the picture and yield valuable findings for future $Z$. abelicea conservation approaches. Recently, new conservation efforts and field studies have been reactivated on Crete, Greece. The results of our study will be included in local conservation action plans, in collaboration with relevant scientific and conservation institutions on Crete, e.g. with the Mediterranean Agronomic Institute in Chania (MAICh) and with the Forest Directorate of Chania (FDC).

Our study shows that the ex situ collections have overall significantly lower gene diversities than those calculated for the in situ polymorphic populations, and lower numbers of haplotypes than expected under random sampling of wild populations for both species. This result is an indication that, for both species, the lower records for the ex situ trees are not due to lower sampling, because these two measures are corrected for sampling size, but rather to biased sampling. The bias is however higher for Z. abelicea than for $Z$. carpinifolia. The way collections were established can account for this lower diversity as they were partly built on seed, seedlings and cutting exchanges between botanical gardens. 
For example, the high representation of haplotypes JT, especially in botanical gardens sampled in the UK, could be linked to the presence of this haplotype in natural populations that are part of the botanical garden of Tbilisi in Georgia (Table 1; Christe et al. 2014). This botanic garden was indeed proposing Z. carpinifolia seeds in his Index Seminum since at least the late 19th century (Christe C., pers. comm.).

Furthermore, our study revealed that $8 \%$ of ex situ trees collected for our survey had been incorrectly identified and actually belong to other Ulmaceae genera (e.g., Ulmus) or even to other families (Betulaceae). Four samples described as Z. carpinifolia were misidentified at the species level and actually belonged to eastern Asiatic members of the genus.

This study highlights the need for re-evaluating the viability of living ex situ collections of trees, especially relict trees, and the development of new strategies for future conservation efforts by botanic gardens and arboreta. From our study we therefore draw the following general conclusions and recommendations:

(1) For newly created ex situ collections, only well-documented plant material with detailed information of its origin should be used, and for existing, often very old collections, a thorough investigation of the provenance data for all relict trees under cultivation should be undertaken. For Zelkova, the study of Christe et al. (2014) showing that the western Eurasian species are highly structured was helpful and could be used to assign a putative origin to trees without any available provenance information. However, finding such a strong genetic structure associated to a high diversity using chloroplast sequences is rare for tree species (Magri et al. 2007; Rodríguez-Sánchez et al. 2009; Caetano and Naciri 2011), and the use of trnH-psbA and $t r n \mathrm{~L}$ might not be as successful in other relict tree species.

(2) For relict genera with several species, conservation priority should be given to the most threatened taxa and/or to narrow endemics. For the most threatened relict tree species and/or genera, well-coordinated specialist groups should be created to act globally to develop a long-term ex situ conservation strategy for these taxa. These specialist groups should define, among other things, the geographical distribution of ex situ collections and should ensure the genetic and biogeographical representativeness of the plant material used.

(3) Botanic gardens and arboreta in regions and countries with emblematic relict trees should integrate the ex situ conservation of these taxa into their conservation strategies and action plans.

(4) Further research concerning the minimum number of cultivated trees per botanic garden and taxon to ensure the conservation of a maximum of the genetic diversity for a given taxon should be carried out.

(5) For relict trees at the brink of extinction, maintaining living ex situ collections should be accompanied by other ex situ conservation methods and approaches, e.g., cryopreservation of seeds, pollen, propagules, etc. frozen in liquid nitrogen; seed banking with seeds stored under low moisture and temperature; or in vitro tissue culture and propagation.

Acknowledgments We would like to thank B. Clément and S. Bollinger from the Botanical Garden of the University of Fribourg (Switzerland); E. Gerber and A. Fasel from the Natural History Museum Fribourg (Switzerland); M. Jafari (University of Teheran, Iran) and Y. Marbach, B. Egli and R. Keller (Switzerland) for their assistance during the manuscript preparation. We are indebted to the Franklinia Foundation for its generous support provided to undertake this study and to the City of Geneva, the Société Académique de Genève and the Prof. R. Spichiger (University of Geneva) for the funds they provided to buy a new 
automated sequencer. Special thanks go to D. Gibbs from Botanic Gardens Conservation International (BGCI), who coordinated the data and sample exchange, and to V. Ali-zade, E. Alirzayeva, E. Maharramova (Azerbaijan National Academy of Sciences), H. Safarov (Hyrcanian National Park), M. Khutsishvili (National Botanic Garden of Georgia, Tbilisi) for the field work coordination and sampling in Azerbaijan and Georgia. The permission to collect Z. abelicea plant material was granted by the Ministry of the Environment, General Directorate of Forests, Department of Aesthetic Forests, National Parks and Wildlife Management, Athens, Greece (199076/1843). Many botanic gardens and arboreta around the world provided samples for the present survey-their contributions are gratefully acknowledged: Arboretum Kórnickie, Poland; Aristotle University of Thessaloniki, Greece; Botanic Garden of the University of Poznan, Poland; Botanic Gardens of Adelaide, Australia; Botanische Gärten der Universität Bonn, Germany; Botanischer Garten der Universität Zürich, Switzerland; Botanischer Garten der Universität Bern, Switzerland; Botanischer Garten der Universität Freiburg, Switzerland; Conservatoire et Jardin botaniques de la Ville de Genève, Switzerland; Parc Floraire, Switzerland; Botanischer Garten und Botanisches Museum Berlin Dahlem, Germany; Cambridge University Botanic Garden, United Kingdom; Chicago Botanic Garden, United States of America; Garten der Johannes Gutenberg Universität Mainz, Germany; Jardí Botànic de Barcelona, Spain; Jardin Botanique de la Ville de Paris, Ecole du Breuil, France; Jardin Botanique de l'Université de Strasbourg, France; Jardins des Plantes et Arboretum de Chevreloup, France; Kutaisi Botanical Garden, Georgia; Morris Arboretum, United States of America; National Botanic Gardens of Ireland, Ireland; Royal Botanic Gardens, Kew, United Kingdom; Royal Veterinary and Agricultural University Arboretum, Denmark; Stichting Arboretum Wespelaar, Belgium; Syon Park, United Kingdom; The Dawes Arboretum, United States of America; The Royal Horticultural Society's Garden, Wisley, United Kingdom; The Sir Harold Hillier Garden and Arboretum, United Kingdom; and Westonbirt Arboretum, United Kingdom.

\section{References}

Bandelt HJ, Foster P, Röhl A (1999) Median-joining networks for inferring intraspecific phylogenies. Mol Biol Evol 16:37-48

Barriel V (1994) Phylogénies moléculaires et insertions-délétions de nucléotides. C R Acad Sci Paris 317:693-701

BGCI (Botanic Gardens Conservation International) (2010) Global survey of ex situ Zelkova collections. http://www.bgci.org/files/survey-zelkova.pdf. Accessed 28 Nov 2013

Bosque M, Adamogianni MI, Bariotakis M, Fazan L, Stoffel M, Garfì G, Gratzfeld J, Kozlowski G, Pirintsos S (2014) Fine-scale spatial patterns of the Tertiary relict Zelkova abelicea (Ulmaceae) indicate possible processes contributing to its persistence to climate changes. Reg Environ Change 14:835-849

Browicz K, Zielinski J (1982) Chorology of trees and shrubs in south-west Asia and adjacent regions. Polish Academy of Sciences, Institute of Dendrology, Bogucki Wydawnictwo Naukowe, Poznan

Brown AHD, Marshall DR (1995) A basic sampling strategy: theory and practice. In: Gaurino L, Gaurino L, Ramanatha Rao V, Reid R, Reid R (eds) Collecting plant genetic diversity: technical guidelines. CAB International, Wallingford, pp 75-91

Burnham RJ (1986) Foliar morphological analysis of the Ulmoideae (Ulmaceae) from the early Tertiary of western North America. Palaeontogr Abt B 201:135-167

Caetano S, Naciri Y, Naciri Y (2011) The biogeography of seasonally dry tropical forests in South America. In: Dirzo R, Young HS, Mooney HA, Mooney HA, Ceballos G (eds) Seasonally dry tropical forests: ecology and conservation. Island Press, Stanford, pp 23-44

CBD (Convention on Biological Diversity) (2011) Updated global strategy for plant conservation 2011-2020. http://www.cbd.int. Accessed 15 Dec 2013

Chaw S-M, Parkinson CL, Cheng Y, Vincent TM, Palmer DJ (2000) Seed plant phylogeny inferred from all three plant genomes: monophyly of extant gymnosperms, and origin of Gnetales from conifers. Proc Nat Acad Sci USA 97:4086-4091

Christe C, Kozlowski G, Frey D, Bétrisey S, Maharramova E, Garfî G, Pirintsos S, Naciri Y (2014) Footprints of past intensive diversification and structuring in the genus Zelkova (Ulmaceae) in southwestern Eurasia. J Biogeogr 41:1081-1093

Cohen JI, Williams JT, Plucknett DL, Shands H (1991) Ex situ conservation of plant genetic resources: global development and environmental concerns. Science 253:866-872

Connor SE (2009) Human impact—the last nail in the coffin for ancient plants? J Biogeogr 36:485-486

Del Tredici J, Ling H, Yang G (1992) The Ginkgos of Tian Mu Shan. Conserv Biol 6:202-209 
Denk T, Grimm GW (2005) Phylogeny and biogeography of Zelkova (Ulmaceae sensu stricto) as inferred from leaf morphology, ITS sequence data and the fossil record. Bot J Linn Soc 147:129-157

Di Pasquale G, Garfî G, Quezél P (1992) Sur la présence d'un Zelkova nouveau en Sicile sudorientale (Ulmaceae). Biocosme Mésogéen 8-9:401-409

Donaldson JS (2009) Botanic gardens science for conservation and global change. Trends Plant Sci 14:608-613

Egli B (1995) Zelkova abelicea (Lam.) Boiss. In: Phitos D, Strid A, Snogerup S, Greuter W (eds) The red data book of rare and threatened plants of Greece. Michalas K, WWF Greece, Athens, pp 526-527

Egli B (1997) A project for the preservation of Zelkova abelicea (Ulmaceae), a threatened endemic tree species from the mountains of Crete. Bocconea 5:505-510

Ensslin A, Sandner TM, Matthies D (2011) Consequences of ex situ cultivation of plants: genetic diversity, fitness and adaptation of the monocarpic Cynoglossum officinale L. in botanic gardens. Biol Conserv 144:272-278

Etisham-Ul-Haq M, Allnutt TR, Smith-Ramirez C, Gardner MF, Armesto JJ, Newton AC (2001) Patterns of genetic variation in and ex situ populations of the threatened Chilean vine Berberidopsis carollina, detected using RAPD markers. Ann Bot 87:813-821

Excoffier L, Laval G, Schneider S (2005) Arlequin ver. 3.0: an integrated software package for population genetics data analysis. Evol Bioinform Online 1:47-50

Fazan L, Stoffel M, Frey D, Pirintsos S, Kozlowski G (2012) Small does not mean young: age estimation of severely browsed trees in anthropogenic Mediterranean landscapes. Biol Conserv 153:97-100

Garfî G (2006) Zelkova sicula. IUCN red list of threatened species. Version 2013.2. http://www.iucnredlist. org. Accessed 28 Nov 2013

Garfî G, Carimi F, Pasta S, Rühl J, Trigila S (2011) Additional insights on the ecology of the relic tree Zelkova sicula di Pasquale, Garfî et Quézel (Ulmaceae) after the finding of new population. Flora 206:407-417

Güner A, Zielinski J (1998) Zelkova carpinifolia. IUCN red list of threatened species. Version 2013.2. http:// www.iucnredlist.org. Accessed Nov 2013

Hall TA (1999) BioEdit: a user-friendly biological sequence alignment editor and analysis program for Windows 95/98/NT. Nucl Acids Symp Ser 41:95-98

Kozlowski G, Gratzfeld J (2013) Zelkova - an ancient tree. Global status and conservation action. Natural History Museum Fribourg, Switzerland

Kozlowski G, Gibbs D, Fun H, Frey D, Gratzfeld J (2012a) Conservation of threatened relict trees through living ex situ collections: lessons from the global survey of the genus Zelkova (Ulmaceae). Biodivers Conserv 21:671-685

Kozlowski G, Frey D, Fazan L, Egli B, Pirintsos S (2012b) Zelkova abelicea. IUCN red list of threatened species. Version 2013.2. http://www.iucnredlist.org. Accessed 28 Nov 2013

Kozlowski G, Frey D, Fazan L, Egli B, Bétrisey S, Gratzfeld J, Garfî G, Pirintsos S (2014) Tertiary relict tree Zelkova abelicea (Ulmaceae): distribution, population structure and conservation status. Oryx 48:80-87

Kvavadze EV, Connor SE (2005) Zelkova carpinifolia (Pallas) K. Koch in Holocene sediments of Georgiaan indicator of climatic optima. Rev Palaeobot Palynol 133:69-89

Lauterbach D, Burkart M, Gemeinholzer B (2012) Rapid genetic differentiation between ex situ and their in situ source populations: an example of the endangered Silene otites (Caryophyllaceae). Bot J Linn Soc 168:64-75

Ledig FT (1988) The conservation of diversity in forest trees. Why and how should genes be conserved? Bioscience 38:471-479

Li YY, Chen XY, Zhang X, Wu TY, Lu HP, Cai YW (2005) Genetic differences between wild and artificial populations of Metasequoia glyptostroboides: implications for species recovery. Conserv Biol 19:224-231

Magri D, Fineschi S, Bellarosa R, Buonamici A, Sebastiani F, Schirone B, Simeone MC, Vendramin CC (2007) The distribution of Quercus suber chloroplast haplotypes matches the paleogeographical history of the western Mediterranean. Mol Ecol 16:5259-5266

Mai DH (1995) Tertiäre vegetationsgeschichte Europas. Methoden und Ergebnisse, Gustav Fischer

Maunder M, Havens K, Guerrant EO Jr, Falk DA, Falk DA (2004) Ex situ methods: a vital but underused set of conservation resources. In: Guerrant EO Jr, Havens K, Maunder M (eds) Ex situ plant conservation. Supporting species survival in the wild. Island Press, Covelo, pp 3-20

Milne RI (2006) Northern Hemisphere plant disjunctions: a window on Tertiary land bridges and climate change? Ann Bot 98:465-472

Milne RI, Abbott RJ (2002) The origin and evolution of tertiary relict floras. Adv Bot Res 38:281-314 
Namoff S, Husby CE, Francisco-Ortega J, Noblick LR, Lewis CE, Griffith MP (2010) How well does a botanic garden collection of rare palm capture the genetic variation in a wild population? Biol Conserv 143:1110-1117

Nei M (1973) Analysis of gene diversities in subdivided populations. Proc Natl Acad Sci USA 70:3321-3323

Oldfield SF (2009) Botanic gardens and the conservation of tree species. Trends Plant Sci 14:581-583

Petit RJ, El-Mousadik A, Pons O (1998) Identifying populations for conservation on the basis of genetic markers. Conserv Biol 12:844-855

Petit RJ, Hampe A, Cheddadi R (2005) Climate change and tree phylogeography in the Mediterranean. Taxon 54:877-885

Phitos D, Strid A, Snogerup S, Greuter W (eds) (1995) The Red Data Book of rare and threatened plants of Greece. Michalas K, WWF Greece, Athens

Primack RB (2004) A primer of conservation biology, 3rd edn. Sinauer Associates, Inc Publishers, Sunderland

Quézel P, Médail F (2003) Ecologie et biogeography des forêts du bassin méditerranéen. Elsevier, Paris

Rodríguez-Sánchez F, Guzmán B, Valido A, Vargas P, Arroyo J (2009) Late Neogene history of the laurel tree (Laurus L., Lauraceae) based on phylogeographical analyses of Mediterranean and Macaronesian populations. J Biogeogr 36:1270-1281

Rucinska A, Puchalski J (2011) Comparative molecular studies on the genetic diversity of an ex situ garden collection and its source population of the critically endangered polish endemic plant Cochlearia polonica E. Fröhlich. Biodivers Conserv 20:401-413

Shaw J, Lickey EB, Beck JT, Farmer SB, Liu W, Miller J, Siripun KC, Winder CT, Schilling EE, Small RK (2005) The tortoise and the hare II: relative utility of 21 noncoding chloroplast DNA sequences for phylogenetic analysis. Am J Bot 921:142-166

Søndergaard P, Egli BR (2006) Zelkova abelicea (Ulmaceae) in Crete: floristics, ecology, propagation and threats. Willdenowia $36: 317-322$

Taberlet P, Gielly L, Patou G, Bouvet J (1991) Universal primers for amplification of three noncoding regions of chloroplast DNA. Plant Mol Biol 17:1105-1109

Trueman SJ, Pegg GS, King J (2007) Domestication for conservation of an endangered species: the case of the Wollemi Pine. Tree For Sci Biotech 1:1-10

Whitlock BA, HaleAM, Groff PA (2010) Intraspecific inversions pose a challenge for the trnH-psbA plant DNA barcode. PloS One 5(7):e11533. doi:10.1371/journal.pone.0011533

Wiegrefe SJ, Sytsma KJ, Guries RP (1998) The Ulmaceae, one family or two? Evidence from chloroplast DNA restriction site mapping. Plant Syst Evol 210:249-270

Wyse Jackson P, Kennedy K (2009) The Global Strategy for Plant Conservation: a challenge and opportunity for the international community. Trends Plant Sci 14:578-580

Yang RC, Yeh FC (1992) Genetic consequences if in situ and ex situ conservation of forest trees. Forest Chron 68:720-729

Zheng-Yi W, Raven PH (eds) (2003) Zelkova. Flora of China, Vol. 5. Ulmaceae-Basellaceae. Missouri Botanical Garden Press, St. Louis 